\title{
Governança de Pequenas Empresas Familiares BRASILEIRAS: ASPECTOS A CONSIDERAR NO MODELO ADOTADO
}

\author{
Governance in Brazilian Small Family Business: aspects to \\ consider in model adopted
}

\author{
Rodrigo Teixeira Machado \\ Especialista em Marketing (FGV). Especialista em Gestão de Pessoas (UPF). Orientador Comercial - Passo Fundo - RS - Brasil. E-mail: \\ rodrigo.machado12@hotmail.com
}

\section{Denize Grzybouski}

Doutora em Administração (UFLA). Professora e Pesquisadora no curso de Administração na Faculdade de Ciências Econômicas, Administrativas e Contábeis na Universidade de Passo Fundo (FEAC/UPF). Professora Convidada no Programa de Pós-Graduação em Desenvolvimento (UNIJUÍ). - Passo Fundo - RS - Brasil.E-mail: gdenize@upf.br

\section{Enise Barth Teixeira}

Doutora em Engenharia de Produção (UFSC). Professora da Universidade Federal da Fronteira Sul (UFFS) - Chapecó - SC - Brasil. E-mail: enise.teixeira@uffs.edu.br

\section{Margarete David da Silva}

Estudante de Administração. Bolsista de Iniciação Científica CNPq - Faculdade de Ciências Econômicas, Administrativas e Contábeis na Universidade de Passo Fundo (FEAC/UPF). - Passo Fundo - RS - Brasil. E-mail: 118131@upf.br

\section{Resumo}

O objetivo deste trabalho é discutir o conceito, o modelo e a estrutura de governança, apropriados à gestão de pequenas empresas familiares brasileiras, pois essa governança pode minimizar problemas de agência relativos à família proprietária. Governança é um instrumento de controle e de gestão que coloca em sintonia as empresas e o mercado, o qual contempla a relação da empresa com os stakeholders. Este estudo é uma pesquisa exploratória e descritiva, do tipo estudo de caso, com abordagem qualitativa dos dados. Os resultados indicam que a estrutura de governança adotada na empresa familiar analisada não é condizente com nenhum modelo presente na literatura, a qual enfatiza a grande empresa e a governança corporativa. O caso estudado apresenta particularidades e dinâmica coerentes com as características da família proprietária, com sistemas fracamente estruturados e processo decisório pautado na dinâmica do mercado.

Palavras-chave: Governança. Modelos. Pequena Empresa. Empresa Familiar.

\section{Abstract}

The aim is to discuss the concept and model as well as the governance structure appropriate to the management of small family businesses in Brazil, because this can minimize agency problems related to family ownership. Governance is an instrument of control and management that puts the companies in line with the market, which includes the company's relationship with stakeholders. This study is an exploratory and descriptive research, the case study with a qualitative approach. The results indicate that the governance structure adopted in the family business is not considered consistent with any model in the literature, which emphasizes the large enterprise and corporate governance. The studied case presents peculiarities and dynamics consistent with the characteristics of the owning family, with loosely structured systems and decision-making process guided by the market dynamics.

Keywords: Governance. Model. Small Business. Family Business. 


\section{INTRODUÇÃo}

Antes de começar deseja-se agradecer à Fapergs, pelos recursos disponibilizados para o desenvolvimento deste estudo, e ao CNPQ, pela bolsa de iniciação científica.

Em mercados nos quais prolifera o capitalismo e em tempos de globalização econômica, há crescente evolução dos mecanismos de controle e de gestão dos recursos, em especial quando proprietários também são gestores em grandes corporações (FAMA; JENSEN, 1983; BEBCHUK; WEISBACH, 2010; LI; SRINIVASAN, 2011). Com o caso emblemático da Enron (CLARKE, 2004), a recente crise no setor imobiliário nos Estados Unidos e a consequente crise no sistema financeiro mundial, evidenciaram-se algumas fraquezas nos mecanismos de governança adotados até então para resolver problemas de agência (JENSEN, 2000; PEREIRA, 2008) e para compreender seus efeitos nas decisões estratégicas das empresas familiares (MUSTAKALLIO et al., 2002). As organizações têm buscado adotar novos mecanismos que permitam avaliar com maior credibilidade seus resultados e promover a sua sustentabilidade financeira (SIFFERT FILHO, 1998; GUEDES; FARIA, 2004; MIZUMOTO; MACHADO FILHO, 2007; CHONG; LÓPEZ-DE-SINALES, 2007; BROUARD; DI VITO, 2008; IBGC BOOZ ALLEN, 2010). Dessa forma, todos os agentes econômicos esperam obter crescimento sustentado no mercado, controle do uso e aplicação dos recursos, bem como capacidade de endividamento projetada e alinhada às tendências do segmento de atuação. Tudo isso passa pela necessidade de aprimoramento dos princípios e mecanismos de governança, dos quais as empresas brasileiras familiares de pequeno porte não estão excluídas.

O objetivo deste estudo é discutir o conceito e o modelo, bem como a estrutura de governança, adequados à gestão de pequenas empresas familiares brasileiras, pois estas empresas enfrentam crises no seu ciclo de vida (PADULA, 1998), que comprometem a sobrevivência organizacional, geralmente em função das implicações da não separação da propriedade e controle e da sobreposição de funções entre sócios e gestores (MUSTAKALLIO et al., 2002; IBGC, 2011). A adoção de um modelo de governança pode minimizar problemas de agência relativos à família proprietária.
O estudo se justifica pela ausência do debate do tema governança em empresas familiares de pequeno porte (BEBCHUK; WEISBACH, 2010), pois a maioria da literatura versa sobre grandes corporações (IBGC BOOZ ALLEN, 2003), com capital aberto (RENDERS; GAEREMYNCK, 2012) e os modelos apresentados são para implementação da governança corporativa. Mesmo assim, no Brasil, o debate encontra-se restrito a algumas poucas publicações, pois a imagem da empresa familiar, em especial a de pequeno porte, é de um tipo organizacional que não adota mecanismos formais de controle e de gestão. Sistemas fracamente estruturados têm sido apontados pela literatura brasileira sobre empresa familiar como sendo um elemento causador de problemas de agência e que contribuem para a mortalidade de empresas familiares brasileiras. (SIFFERT FILHO, 1998; MONACO, 2000; SOUZA, 2005; MIZUMOTO; MACHADO FILHO, 2007)

Os resultados deste estudo estão apresentados a seguir, em quatro partes. A primeira apresenta os fundamentos teóricos sobre governança no mundo e no contexto brasileiro. A segunda parte apresenta os fundamentos metodológicos que orientaram o estudo empírico. A terceira e quarta partes apresentam os resultados da investigação, o modelo de estrutura de governança corporativa adequada para pequenas empresas e, na sequência, as conclusões do estudo.

\section{Governança: a ÊNFASE EM CORPORAÇÕES}

No Brasil e no mundo, governança tornou-se tema-alvo de debate nesta última década, em especial em função dos escândalos envolvendo organizações globais, como Enron (CLARKE, 2004). A forma como organizações controlam o problema de agência causada pela separação (ou não) de propriedade e controle tem sido uma preocupação para pesquisadores desde Smith (1776) e Berle e Means (1932) até Jensen e Meckling (1976), Fama (1980) e Fama e Jensen (1983). Nessa parte inicial da literatura revisada, apresentam-se os aspectos conceituais da governança corporativa $e$ um apanhado geral do tema governança no Brasil e no mundo para, então, inserir o tema no contexto da empresa familiar. 


\subsection{Aspectos Conceituais}

O desenvolvimento econômico de um país pode ser determinado pelo nível de sua atividade empresarial (SCHUMPETER, 1968), forma de realização do trabalho para gerar riqueza (SMITH, 1776), mas também a estrutura de controle (coordenação de atividades dentro da empresa) no nível de decisão que as organizações adotam (JENSEN; MECKLING, 1976; FAMA, 1980; FAMA; JENSEN, 1983). Não é exagero afirmar que os pilares da economia de cada nação se alicerçam na eficiência de suas empresas (SMITH, 1776; SCHUMPETER, 1968; EMRICH; BAÊTA, 2007), assim como na responsabilidade dos gestores em alocação das variáveis que compõem a função de produção, a qual está diretamente relacionada à maximização do valor da empresa e a seus proprietários (CLARKE, 2004). Essa eficiência se traduz pela capacidade de produção e de geração de empregos, que decorre diretamente da aptidão das companhias de financiar seus investimentos, visando à redução de custos e a melhoria da qualidade de seus produtos e serviços. (EMRICH; BAÊTA, 2007; MIZUMOTO; MACHADO FILHO, 2007)

Com o objetivo de aprimorar a relação entre as empresas e o mercado investidor, surgiu na economia anglo-saxônica um movimento posteriormente denominado corporate governance, que alcançou o Brasil em meados da década de 1990, como subproduto da globalização (ZINGALES, 1998; IBGC BOOZ ALLEN, 2003; ARAUJO; ESPOSITO, 2004), e foi aqui rotulado segundo sua tradução literal: governança corporativa. (IBGC, 2011)

Para fins do presente estudo, governança é considerada um instrumento de controle e de gestão que coloca em sintonia as empresas com o mercado, abrangendo não só a relação com os acionistas presentes $e$ potenciais, mas também fornecedores, consumidores, membros da família proprietária e a coletividade. (SOUZA, 2005)

De acordo com Zingales (1998), IBCG (2011) e Mckinsey (2001), a governança é uma ampla área de pesquisa envolvendo finanças, economia e direito, fortemente orientada pelas teorias de agência, a qual propõe a visão contratual da firma e reforma o problema clássico de quem monitora o monitor (CLARKE, 2004), e pelas teorias de stakeholders e do acionista, na qual a premissa básica é a maximização do lucro, a criação do valor e a orientação para valor. (FAMA; JENSEN, 1983; JENSEN, 2000)

O movimento em torno do tema é algo recente, tanto na academia quanto no mercado corporativo, com as áreas temáticas se intensificando a partir da década de oitenta (BEBCHUK; WESIBACH, 2010), como apontam os encontros sobre projetos de governança corporativo da National Bureau of Economic Research (NBER). Zingales (1998) afirma que o próprio termo governança não existia na literatura de administração nos inícios dos anos oitenta. Mesmo hoje ele estando popularizado em nível global, as empresas brasileiras têm demonstrado pouca adesão às práticas de governança, como apontam os relatórios do IBGC (IBGC/ BOOZ ALLEN, 2003, 2010), talvez pelo foco na corporação, ou seja, em grandes organizações.

\subsection{Governança no Mundo}

A teoria, o sistema e as práticas de governança adotadas pelas empresas dependem, em grande parte, do ambiente institucional no qual elas estão inseridas (JUDGE, 2012). O Estado, através da definição dos sistemas financeiro e legal, modela a formação do mercado de capitais local e do grau de proteção dos investidores, influenciando o modelo de governança adotado pelas empresas, bem como o rigor de controle nos conselhos, em especial das empresas com capital aberto (HE; SOMMER, 2006; LI; SRINIVASAN, 2011; RENDERS; GAEREMYNCK, 2012). A transparência dos resultados econômicos obtidos pelas empresas requer mecanismos formais de governança e a presença do Estado na determinação do rigor no controle dos resultados das empresas faz com que os países apresentam diferenças significativas entre os sistemas de governança das suas empresas, sejam elas familiares ou não. (ARAUJO; ESPOSITO, 2004; MIZUMOTO; MACHADO FILHO, 2007; LI; SRINIVASAN, 2011; RENDERS; GAEREMYNCK, 2012)

A maior parte das economias de mercado avançadas tem resolvido seu problema de governança de uma forma no mínimo razoável, garantindo enormes fluxos de recursos para as empresas e o retorno dos lucros aos fornecedores de recursos (MARINELLI, 2005). Por essa razão as economias dos países impactam na estrutura dos sistemas de governança. 
De acordo com Araújo e Espósito (2004), existem diferenças acentuadas entre os melhores sistemas de governança do mundo, como o anglo-saxão, o alemão e o japonês, mas as diferenças entre eles são provavelmente menores do que as diferenças com relação aos outros países menos desenvolvidos. Os mecanismos de governança da Itália são tão subdesenvolvidos que retardam de forma substancial o fluxo de capitais externos para as empresas (MARINELLI, 2005). A limitação no grau de separação entre propriedade e controle e a grande estabilidade dos controladores nas empresas dificultam a presença de um mercado de aquisição hostil, obstruindo as reestruturações necessárias e limitando as oportunidades das pessoas (MARINELLI, 2005). No Reino Unido ou nos Estados Unidos, as ações estão amplamente pulverizadas e os problemas das empresas geralmente estão associados ao conflito clássico entre uma administração profissional e uma base de acionistas ampla e difusa. No Brasil, a principal fonte de conflitos decorre do relacionamento entre os acionistas controladores e os minoritários. A estrutura de controle brasileira, altamente concentrada, $e$ a falta de proteção aos direitos dos acionistas minoritários estão por detrás dos problemas mais relevantes de governança. Contudo, os blocos de controle geram preocupações de governança diferentes das que ocorrem em mercados desenvolvidos.

\subsection{O Debate sobre Governança no Brasil}

No Brasil, antes da introdução da nova legislação das sociedades anônimas, os acionistas controladores deparavam com um incentivo perverso de enfatizar as más notícias e deprimir o preço das ações, principalmente no caso de mudança de controle, para induzir os acionistas minoritários a aceitarem ofertas de preços menores. Essa assimetria de informações priva o acionista minoritário do conhecimento e, portanto, do direito de receber um valor justo por sua posição acionária. Os esforços do Brasil para eliminar tais distorções incluem as alterações na Lei das Sociedades Anônimas e na Lei do Mercado de Valores Mobiliários, além da introdução do Novo Mercado - no qual as companhias listadas nele possuem padrões de governança mais elevados do que os exigidos pela legislação. A criação do Novo Mercado e outras alterações na Lei do Mercado de Valores Mobiliários, afirmam Araújo e
Espósito (2004), enfatizam a promoção da dispersão acionária, a melhor divulgação de informações e a transparência e a proteção dos direitos dos acionistas minoritários, esforços estes complementados pela maior regulamentação para a auditoria e para os profissionais responsáveis pela sua execução.

Apesar de as principais formas de constituição das companhias abertas no Brasil (empresas privadas nacionais, estatais e subsidiárias de multinacionais) gerarem diferentes modelos de governança, a pesquisa realizada pelo IBCG (2001), McKinsey \& Company e Korn/Ferry Internacional (2001) permite traçar um modelo geral de governança para as empresas brasileiras listadas em bolsa, com as seguintes características:

a) Estrutura de propriedade com forte concentração das ações com direito a voto (ordinárias) $e$ alto índice de emissão de ações sem direito a voto (preferenciais).

b) Empresas com controle familiar ou compartilhado por alguns poucos investidores alinhados por meio de acordo de acionistas para resolução das questões relevantes.

c) Presença de acionistas minoritários pouco ativos.

d) Alta sobreposição entre propriedade e gestão, com os membros do conselho representando os interesses dos acionistas controladores.

e) Pouca clareza na divisão dos papéis entre conselho e diretoria, principalmente nas empresas familiares.

f) Escassez de conselheiros profissionais no Conselho de Administração.

g) Remuneração dos conselheiros como fator pouco relevante.

h) Estrutura informal do Conselho de Administração, com ausência de comitês para tratamento de questões específicas, como auditoria ou sucessão.

A forte concentração das ações com direito a voto é característica fundamental do modelo de governança das companhias pulverizadas. Segundo Monaco (2000), os acionistas controladores detêm, em média, $88 \%$ das ações emitidas com direito a voto.

Como decorrência da grande concentração de poder, os membros do Conselho de Administração são em sua grande maioria indicados pelo acionista controlador. Essa situação reduz a possibilidade de 
uma postura ativa e independe dos conselhos, que é necessária para o cumprimento de suas atribuições legais de fixação da orientação geral dos negócios e fiscalização da gestão dos executivos em prol de todos os acionistas.

Nas empresas familiares, em geral os conselheiros não são profissionais, sendo indicados pelo controlador por laços familiares ou pessoais, prejudicando a qualidade da análise das questões estratégicas da companhia. (KRUGER; GOMES, 2008)

Algumas mudanças ocorridas nos anos de 1990, como o aumento de competitividade decorrente da maior estabilidade econômica e abertura de mercado, além da maior dificuldade de obtenção de financiamento estatal têm levado as empresas brasileiras a uma necessidade crescente de acesso aos mercados de capitais nacionais e internacionais. Essa necessidade de obtenção de recursos ao menor custo possível tem motivado as empresas a adotarem novas práticas de governança, pressionando o atual modelo de governança brasileiro (KRUGER; GOMES, 2008), principalmente nos aspectos de maior consideração dos interesses dos acionistas minoritários, maior transparência das informações ao mercado e profissionalização do conselho de administração das empresas.

De acordo com o estudo desenvolvido pela McKinsey \& Company/Korn/Ferry International, em 2001, as empresas com forte liderança e capacidades financeiras e que conseguiram ser bem-sucedidas no Brasil determinaram o modelo atual de governança. Esse modelo caracteriza-se por uma forte concentração da propriedade em apenas alguns acionistas majoritários. Em geral, os três maiores acionistas detêm, em média, $85 \%$ do total das ações ordinárias. Essa estrutura de propriedade resulta numa sobreposição entre propriedade e liderança executiva, na qual os membros do conselho representam o interesse dos acionistas controladores ou majoritários, e os acionistas minoritários são pouco ativos. Além disso, as estruturas e os procedimentos de governança são geralmente informais. Por exemplo, $44 \%$ de membros de conselhos responderam que não existem subcomitês constituídos em suas empresas e somente $11 \%$ estão satisfeitos com os processos atuais.

O mesmo estudo constatou que está ocorrendo uma mudança no modelo de governança no Brasil rumo a um "modelo emergente" de governança, o qual é caracterizado por maior profissionalismo. Nesse modelo, as estruturas do conselho e seus processos são bem definidos, e os conselheiros têm melhor qualificação para lidar com questões estratégicas. Além disso, os acionistas minoritários estão se tornando mais ativos. No entanto, a estrutura de propriedade permanece com uma alta concentração da propriedade, e a sobreposição entre propriedade e liderança executiva continua. Esse crescente profissionalismo, embora encontre alguma resistência por parte de alguns conselheiros controladores, vem contribuindo para reforçar a postura estratégica do conselho, tornar os processos decisórios mais eficientes, estabelecer um melhor relacionamento com os mercados de capitais e os órgãos de regulamentação e, por fim, levar mais em consideração os interesses dos acionistas minoritários.

Nas empresas familiares brasileiras também se observa movimento em direção a profissionalização da gestão, tanto nas grandes quanto nas pequenas $e$ médias empresas. Nas empresas familiares, a questão da informalidade dos processos e sobreposição entre propriedade e liderança sempre foram problemas graves de governança (CARRIERI; SARAIVA; GRZYBOVSKI, 2008; BORNHOLDT, 2005). Nesse sentido, no contexto brasileiro, os custos de agência, originários de problemas na separação de propriedade e controle das organizações, ganham uma perspectiva maior quando se trata de empresas familiares.

\section{Governança em Empresa Familiar}

O governo da empresa familiar possui particularidades que vão além dos sistemas "família", "sociedade", "empresa" e todas suas interfaces nas dimensões financeiras, jurídica e afetiva (BORNHOLD, 2005). A complexidade das relações familiares na empresa está diretamente relacionada com a estrutura de governança adotada, como bem apontam Mizumoto e Machado Filho (2007, p. 15): “[...] os problema associados ao 'entrincheiramento' da gestão do negócio na família e à confusão de patrimônio foram minimizados com a adoção das estruturas de governança”.

Por que isso ocorre? Porque a empresa familiar é uma empresa onde a família põe o dinheiro e os sonhos, que naturalmente são modificados com as gerações seguintes sem que a empresa faça as mesmas 
adequações. Esta empresa, ao contrário daquela, precisa estar em sintonia com o mercado e público consumidor, não com a família proprietária. Talvez, por isso, Bernhoeft (1991) afirma que a interação da empresa familiar com a família resulta em influência recíproca na política geral da firma e nos interesses e objetivos da família, dificultando sobremaneira a separação de propriedade e controle (FAMA; JENSEN, 1983), com implicações importantes na composição do conselho gestor. (HE; SOMMER, 2006)

Em termos estruturais e de controle, as empresas familiares brasileiras diferenciam-se de outros países em razão do contexto histórico, em que se observam "comportamentos lógicos" (BERNHOEFT; GALLO, 2003) que visam manter o status quo do fundador, com destaque para: (a) atrasar a sucessão, que visa prolongar o exercício do poder; (b) resistência à mudança espelhada na dificuldade de adequar o negócio às mudanças do ambiente competitivo.

Uma primeira característica comum, e muito importante, do empreendimento privado brasileiro pode ser notada através de uma observação cuidadosa de nossa história (GONÇALVES, 2000). A colonização portuguesa deixou para trás um país atrasado no que diz respeito à educação a industrialização. Não só por esse motivo, mas também por sua juventude inexplorada, o Brasil se constituía, ao final do século passado, numa região onde praticamente tudo estava por ser feito. (GONÇALVES, 2000)

Por trás de um ciclo econômico brasileiro houve sempre uma categoria de empreendedor que abandonou o conforto do conhecido, ainda que sua realidade de origem fosse pouco ou nada promissora, como no caso dos imigrantes italianos, para se aventurar por terras desconhecidas e selvagens e mercados incipientes, sem qualquer regulamentação (GONÇALVES, 2000; CARRIERI; SARAIVA; GRZYBOVSKI, 2008). O gosto por aventura e poder, representado pelas conquistas das propriedades rurais dos ciclos do açúcar e café, caracterizou o empreendimento privado brasileiro.

Nesse contexto, afirmam Grzybovski e Tedesco (2000), a ascensão social conseguida através do trabalho árduo, da luta contra dificuldades enormes e frequentemente auxiliadas apenas por familiares próximos, como esposa $e$ filhos, gerou um apego excessivamente sentimental ao patrimônio, o que produziu grande aversão à divisão da propriedade do negócio, ainda que fundada no objetivo do crescimento através de um grande projeto.

O apego ao patrimônio predomina ainda hoje em grande parte das empresas brasileiras (CARRIERI; SARAIVA; GRZYBOVSKI, 2008), reforçando o modelo de gestão patriarcal, com poder absoluto, inquestionável, indivisível e insubstituível (GRZYBOVSKI; TEDESCO, 2000; BORNHOLDT, 2005). A passagem para um modelo de gestão mais descentralizado, com delegação de poder e responsabilidade e, sobretudo, monitoramento eficiente, é a chave para um crescimento equilibrado e promissor e se constitui num dos maiores desafios a governança em empresa familiar marcadamente a brasileira.

Segundo Efeiche (2009), o conceito de governança para pequenas e médias empresas aplica-se na transparência do próprio negócio e não a fim de melhorar o acesso ao mercado, como é com as grandes corporações. O objetivo, de acordo com ele, é melhorar a comunicação com a própria equipe. "Neste caso, a equipe do empresário seria bancos, fornecedores e clientes, e não acionistas, como no caso das empresas de capital aberto. A adoção de práticas mais transparentes leva, em um segundo momento, ao acesso facilitado de outras formas de capital que não as de curto prazo", completa o executivo.

Ainda, conforme Efeiche (2009), o primeiro passo para melhorar a governança é capturar os principais indicadores e transformá-los em informação gerencial para a análise do próprio empresário. Em um segundo momento, fazer a análise cruzada das informações gerenciais e transformá-las em relatórios operacionais, financeiros e econômicos e até mesmo de sustentabilidade.

Contudo, a operacionalidade desse modelo na pequena empresa familiar brasileira talvez não seja possível efetivar, razão pela qual é preciso descrever um caso e interpretar à luz da teoria aqui apresentada.

\section{Procedimentos Metodológicos}

A presente investigação empírica caracteriza-se como sendo uma pesquisa descritiva, do tipo estudo de caso, desenvolvida com a abordagem qualitativa dos dados (GIL, 1999; YIN, 2005; MARTINS, 2006). Para desenvolver o estudo empírico foi selecionado 
um caso na cidade de Passo Fundo (RS), pelo critério da acessibilidade e disponibilidade do empresário em contar a história da empresa (YIN, 2005), abordagem fundamental para compreender as razões da existência ou não de órgãos de governo na empresa familiar.

Como estudos anteriores apontam, a história da constituição do empreendimento, a complexidade das relações familiares na gestão dos recursos $e$ as questões de poder $e$ autoridade intervenientes no processo decisório são determinantes na compreensão de um sistema de governança útil à pequena empresa familiar. Por essa razão foi necessário adotar uma abordagem qualitativa para análise dos dados, os quais também precisaram ser coletados seguindo o método qualitativo.

Os dados empíricos foram coletados através de entrevistas não gravadas, as quais foram orientadas por um roteiro previamente elaborado, e o seu conteúdo foi transcrito em um caderno de campo. Os sujeitos informantes foram os seguintes membros da empresa: proprietária da empresa, dois gerentes, um funcionário da área administrativa e outro da área comercial. Os dados relativos à estrutura de governança (órgãos, estrutura organizacional, fluxo de processos, sistemas administrativos, outros) foram identificados e analisados de acordo com os modelos de governança descritos na literatura. Para tanto, utilizaram-se desenhos manuais, planilhas eletrônicas (Excel $\left.{ }^{\circledR}\right)$, os quais foram elaborados a partir das observações de campo e dos relatos dos sujeitos informantes. Com base nos dados históricos do empreendimento foram elaborados esquemas e quadros, que contribuíram sobremaneira para compreender a dinâmica do empreendimento $e$ da família na empresa. Os controles internos identificados foram descritos em quadros analíticos e analisadas suas funções operacionais, de controle e de gestão. A análise desse conjunto de dados foi realizada de acordo com a técnica análise de conteúdo. (BARDIN, 2009)

\section{Descrição da Empresa Selecionada para o Estudo de Caso}

Singular Tecnologia é uma empresa especializada em prestação de serviços de tecnologia de comunicação, de infraestrutura de cabeamentos e de softwares para comercialização de produtos e serviços de voz e dados. Com sede em Passo Fundo, uma filial em Caxias do Sul e escritórios em três estados brasileiro, a Singular Tecnologia opera com um quadro de quarenta funcionários, sendo a maioria deles em atividades da área técnica. A gerência geral é realizada pela proprietária, a qual tem 50 anos de idade, com nível superior completo e estrutura familiar constituída de dois filhos $e$ dois netos.

Fundada em junho de 1986, com 25 anos de atuação no mercado regional, a empresa Singular Tecnologia tem sua história vinculada ao espírito empreendedor de sua proprietária, que resolveu empreender quando ainda era funcionária de uma empresa comercial de centrais telefônicas. A origem é típica de uma empresa familiar, operando com apenas quatro pessoas, sendo que três delas eram membros da família da proprietária.

Conforme se pode observar na Figura 1, a proprietária assumiu a responsabilidade sobre as áreas comercial e administrativa, visitando empresas e oferecendo seu produto e serviços. O marido e o irmão assumiram a área técnica, fazendo instalações e realizando manutenção. Apenas uma pessoa não pertencente ao núcleo familiar foi contrata, para exercer a função de secretária, atendendo telefonemas e encaminhando solicitações de clientes.

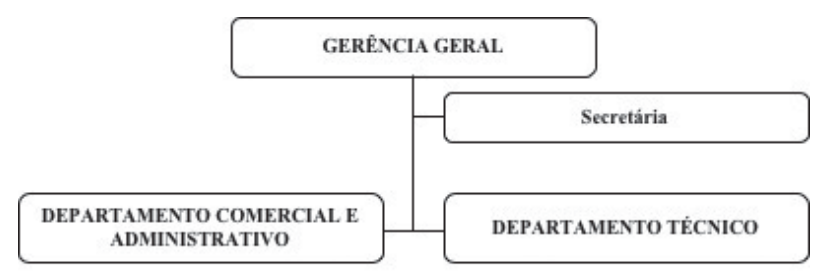

Figura 1: Estrutura organizacional, no momento da fundação do empreendimento

Fonte: Dados da pesquisa (2011)

Passados dez anos de existência da empresa, a sociedade conjugal se encerrou, mas a proprietária deu continuidade à empresa. Mais tarde, ela voltou a constituir matrimônio e seu novso marido, a exemplo do que ocorreu com o primeiro, também ingressou na sua empesa como responsável pela área técnica. Pedro Oliveira, considerado por todos como uma pessoa inovadora, passou a ser a referência na geração de novos conhecimentos, tecnologia e adoção de inovações nos produtos e serviços prestados pela empresa. Tal comportamento do gestor da área técnica conferiu 
à empresa níveis elevados de crescimento; sempre visionário, mantinha o pioneirismo na adoção de novas tecnologias no segmento de atuação.

Em termos de produtos inovadores, a empresa já comercializou marcas de centrais telefônicas (PABX), com destaque para GTE, Alcatel e Ericsson. Ao mesmo tempo, a empresa firmou parcerias com grandes empresas multinacionais na área de cabeamento, com constantes atualizações e certificações para agregarem valor ao seu negócio.

Em termos de produtos inovadores, a empresa sempre tentou ser pioneira nos serviços de tecnologia de voz ao cliente. Em 2005, os técnicos desenvolveram, com software livre, um programa inteligente para substituir o convencional PABX, o que resultou em ampliação de margens de rentabilidade financeira $e$ das atividades nas áreas comercial e técnica. O processo de geração de inovação tecnologia se deu com apoio de uma equipe de consultores externos. Hoje, a empresa possui software de gestão, através do qual é possível gerar relatórios gerenciais e realizar análises administrativas para subsidiar o processo de tomada de decisões.

Uma crise sentida pela empresa foi em 2006 quando Pedro faleceu, pois comprometeu o processo de inovação tecnológica já instalado na empresa. Para manter o ritmo de trabalho foi necessário contratar uma consultoria externa, especializada na área de gestão de pessoas, a qual tinha como tarefa definir os cargos de trabalho. Como resultado foi elaborada uma nova estrutura organizacional, a qual é apresentada na Figura 2.

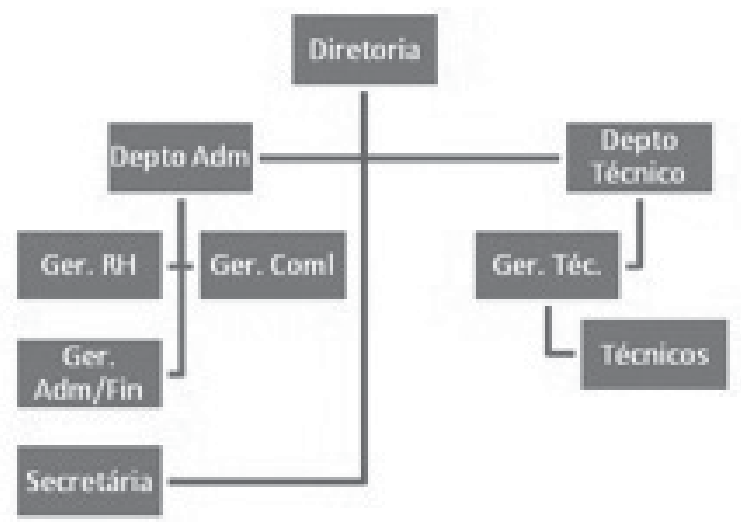

Figura 2: Estrutura organizacional atual

Fonte: Dados da pesquisa (2011)
$\mathrm{Na}$ estrutura organizacional atual, a proprietária continua ostentando a posição hierárquica principal, com o cargo de diretora administrativa. Suas atribuições são estabelecer contatos com clientes fiéis à empresa e os de grande porte. A empresa continua com as características de familiar. O filho continua na área técnica, ocupando o cargo de gerente de projetos e de relacionamento com clientes. Em 2000, a filha também foi inserida na empresa, a qual hoje ocupa o cargo de gerente administrativa e recursos humanos. $\mathrm{Na}$ área técnica também está atuando um parente, o sobrinho da proprietária, que ocupa o cargo de gerente da área técnica. Na equipe de vendas também estava atuando outro sobrinho, no cargo de gerente da equipe de vendedores, mas precisou demiti-lo após perdas sucessivas de contratos; anteriormente ele era membro da equipe de vendedores externos, considerado por todos como o melhor do grupo. A decisão de colocá-lo como gerente da equipe de vendas foi tomada por orientação da equipe de consultores externos.

Com base nas informações coletadas na empresa, pode-se afirmar que a empresa vive uma crise de liderança, enfrenta dificuldades de gestão dos recursos, em especial pela formalização dos cargos no nível gerencial e o consequente incremento nos custos operacionais. Diante disso, a empresária decidiu tomar medidas drásticas para redução de custos e de pessoal: desfez a área comercial, modificou a estratégia de abordagem de clientes e manteve apenas a equipe de técnicos.

A justificativa apresentada pela proprietária para o momento atual da empresa é de que a empresa está sentindo a perda do profissional da área técnica, então seu marido, o qual era o responsável pelos ciclos de renovação de produtos e de serviços. Contudo, não ignora as condições do ambiente de negócios e inclui na lista de fatores o aumento no número de concorrentes e na qualificação destes. A maioria dos concorrentes é considerada por ela como empresas sem qualidade no serviço prestado e sem possuir certificação técnica. Soma-se a esses fatores o posicionamento estratégico do concorrente baseado numa estrutura de preços muito baixo devido a possuírem estrutura operacional enxuto.

Questionada sobre como o mercado externo e as mudanças na economia internacional e nacional influenciavam no seu negócio, a proprietária afirmou que não percebe influência dessas mudanças, pois 
o seu segmento depende da entrada de novas empresas no mercado ou ampliação de indústrias e na inserção de grandes empresas, uma vez que trabalha no atacado. Não atua no varejo por entender que a pequena e média empresa terá sua demanda atendida por equipamentos e softwares que qualquer empresa da área pode comercializar, sem valor agregado e sem manutenção contratada.

\section{Apresentação da Estrutura de Governança Adotada}

Os dados empíricos coletados na empresa Singular Tecnologia revelam que há mecanismos de controle e de gestão que permitem afirmar a existência de um modelo atípico de governança, considerando os modelos identificados na literatura sobre o tema.

A estrutura organizacional e os órgãos de governo na Singular Tecnologia estão bem definidos e a estrutura é efetivamente utilizada para separar as funções de decisão e de apoio, bem como existem mecanismos claros de gestão, que permitem controlar os problemas de agência implícitos e oriundos do sistema familiar, mesmo sem que exista formalmente um comitê gestor ou um conselho de família. Diferentes eventos familiares sustentam essa afirmação, com destaque para a coexistência de duas gerações e as constantes mudanças do estado civil da proprietária, com implicações na estrutura organizacional da empresa.

A análise do sistema de apoio às decisões estratégicas revelou que a empresa utiliza softwares para a coleta de dados e geração de relatórios gerenciais, os quais são usados para a tomada de decisões e controles de investimentos, com destaque para os investimentos em tecnologia que diferenciam a empresa no mercado. Está em processo de construção um novo perfil de clientes que a empresa pretende investir, o qual está sendo elaborado com base nos relatório internos e de mercado.

Mesmo que não existe um Comitê Gestor em funcionamento na empresa, as decisões gerenciais são tomadas em conjunto com os gerentes, em especial com o gerente da área técnica. Após a descrição dos eventos críticos e a análise do ciclo de vida da empresa, chamou a atenção dos autores a decisão gerencial tomada pela proprietária, com base num relatório de consultoria, de estruturar formalmente os cargos e salários na empresa. Passado um tempo, a proprietária decidiu retomar o nível de informalidade antes adotado nas relações de trabalho. A decisão final se deu em função do comprometimento dos recursos financeiros com a folha de salários, algo de difícil execução em empresas familiares de pequeno porte. Contudo, a decisão estratégica de permitir a entrada de investidores para alavancarem o nível de desenvolvimento tecnológico requerido pelo mercado não está descartada, o que reduziria significativamente o caráter familiar da governança.

A estrutura de governança adotada pela empresa Singular Tecnologia, analisada com base nos modelos apresentados no relatório de Mckinsey \& Company/ Korn/Ferry International (2001), não se enquadra em nenhum dos modelos de governança existentes, seja o modelo tradicional ou o modelo emergente. Nesse sentido, afirma-se que na Singular Tecnologia existe um modelo atípico (não descrito na literatura) porque apresenta as seguintes características:

a) A estrutura de propriedade é concentrada apenas na fundadora do empreendimento, que não possui outros acionistas, e estabelece uma relação de sobreposição entre propriedade $e$ gestão executiva.

b) É uma estrutura de propriedade individual, mas a gestão é tipicamente familiar, pois há inserção gradativa de membros do núcleo familiar em níveis de gerência, dentre os quais se destaca, primeiro, o marido, depois os filhos, posteriormente o "novo marido" e o sobrinho.

c) Não existem conselhos formalmente constituídos, apesar de decisões administrativas serem tomadas em reuniões colegiadas numa estrutura informal de conselho familiar.

d) Nas decisões executivas e estratégicas, os processos também não são definidos formalmente, apesar da existência de informações qualificadas transmitidas verbalmente com base nos relatórios de controle do uso e aplicação dos recursos, os quais servem como um frágil sistema de apoio às decisões gerenciais.

e) No que tange à qualidade do quadro funcional, observa-se fragilidade na área técnica, pois há escassez de profissionais capacitados no mercado; a remuneração capaz de ser motivo para a geração da inovação nesta 
área, mostra-se como fator pouco relevante no contexto regional.

Essas particularidades identificadas na empresa analisada, na sua maioria justificadas pelo porte da empresa e por ser de propriedade familiar, conduzem à reflexão crítica sobre a possibilidade de aprimoramento da estrutura de governança com a implantação de alguns controles gerenciais e a adoção de algumas práticas de governança orientadas pelo modelo emergente, citado no estudo de Mckinsey \& Company/Korn/ Ferry International (2001).

A estrutura de propriedade altamente concentrada (apenas uma pessoa) precisa ser repensada para que a empresa tenha sobrevida após o afastamento (voluntário ou compulsório) da pessoa fundadora. Nesse sentido, a estrutura de governança corporativa para empresas familiares de pequeno porte deve contemplar mecanismos para o ingresso gradativo de novos sócios, sejam eles membros ou não da família proprietária, desde que tenham competência profissional (seja na área técnica ou gerencial) e capacidade financeira para alavancar novos projetos que promovam a inovação tecnológica nos produtos e serviços ofertados, bem como na ampliação da capacidade produtiva. Essa estrutura de governança corporativa precisa ser implementada numa plataforma organizacional fracamente estruturada e com filosofia de trabalho e modelo de gestão orientados pela teoria da aprendizagem organizacional transgeracional.

As empresas familiares de pequeno porte, no entanto, não prescindem da coexistência de proprietários-gestores, pois as decisões estratégicas são de sua competência, por tradição e contexto particulares ao Brasil. A gestão executiva poderá ser tema de discussões num órgão colegiado e a escolha poderá recair sobre um membro do núcleo familiar (primeira opção) ou não (segunda opção). Essa proposta tem por base teórica a governança equilibrada na relação propriedade e gestão executiva, com estruturas de integração dos sistemas família-gestão-propriedade apresentada por Mizumoto e Machado Filho (2007).

É preciso considerar a necessidade de estruturação de conselhos de governança. A constituição formal do conselho de família e do conselho administrativo é fundamental também em empresas de pequeno porte. O conselho administrativo, sem remuneração, pode ser composto por conselheiros internos e externos, com vistas a orientar a tomada de decisões estratégicas e tornar a empresa menos dependente de uma única pessoa. Posteriormente, o papel desse conselho poderá evoluir para orientar os interesses dos acionistas, independente do percentual de participação na empresa. Da mesma forma, na empresa familiar de pequeno porte é preciso considerar a possibilidade de estabelecer processos claros e formatados para decisões do cotidiano, em especial com controles formais para acompanhamento rotineiro da evolução dos indicadores. Também é possível utilizar relatórios técnicos como mecanismo decisorial.

Ainda, no que tange ao modelo de gestão de pessoas, é importante adotar plano de capacitação técnica e o estabelecimento de políticas que gerem contratações de profissionais qualificados, experientes. Aos conselheiros, o papel representado com base na experiência em outras empresas é determinante, assim como a qualificação através da interação com profissionais de outras empresas. A política de remuneração orientada por desempenhos e resultados organizacionais é ideal para implementação em empresas com características estruturais de pequeno porte e controle familiar, pois estimula a dedicação e assertividade destes membros. Tudo isso, no entanto, precisa estar atrelado a um plano de remuneração atrativa para contratação de profissionais experientes e com maior capacitação para ocupar cargos estratégicos da empresa, principalmente na área de desenvolvimento de novos produtos e serviços e na área comercial.

\section{Conclusão}

Neste estudo, o objetivo foi discutir o conceito, os modelos e a estrutura de governança, adequados para empresas familiares brasileiras de pequeno porte. O referencial teórico do estudo baseou-se em conceitos usados no mundo e no Brasil para iniciar um debate ausente na literatura brasileira sobre o tema em um estrato da população de empresas.

Ao finalizar este estudo, constatou-se que governança não se refere apenas às corporações, comumente discutida como governança corporativa, mas pode ser discutida para outros tipos organizacionais, mas que requer novo conceito e novos modelos. Nesse sentido, é possível que governança refere-se à estruturação 
de mecanismos de poder e de controle no âmbito da empresa, independente do porte e da propriedade, visando o refinamento do seu processo decisório e a delimitação entre propriedade, família e gestão.

Os achados permitem concluir que o modelo de governança adotado na empresa familiar selecionada para o estudo pouco se assemelha a algum modelo descrito na literatura, o que permite tratá-lo como modelo atípico a ser explorado. As características estruturais e de governança são particulares a empresa familiar brasileira de pequeno porte, com baixo grau de formalização dos processos e práticas de governança relacional, que estimulam o compartilhamento informal de informações entre membros da família. Assim como aponta o IBGC (2011), a governança em empresas familiares brasileiras não se dá apenas no âmbito da separação entre propriedade e controle (FAMA; JENSEN, 1983), mas, também, no âmbito das relações familiares (intrafamiliar) e entre família, patrimônio societário (propriedade) e empresa (gestão). O caso estudado apresenta particularidades e dinâmica coerentes com as características da família proprietária, com sistemas fracamente estruturados e processo decisório pautado na dinâmica do mercado.

O caso da Singular Tecnologia sugere a possibilidade de desenvolvimento de uma estrutura de governança conciliatória entre o espaço privado da família (capaz de contemplar as inseguranças, desejos e sonhos dos seus membros) e o espaço público da empresa (proprietários, funcionários, investidores, fornecedores, clientes), sem que haja "entrincheiramento" e "comportamentos lógicos" que comprometem o desenvolvimento das empresas familiares brasileiras de pequeno porte.

\section{REFERÊNCIAS}

ARAUJO, D.; ESPOSITO, A. Country governance

study: estudos de governance coporativa de países. Standard \& Poor's, mar., 2004.

BARDIN, L. Análise de conteúdo. Ed. revista e actualizada. Lisboa: Edições 70, 2009.

BEBCHUK, L. A.; WEISBACH, M. S. The state of corporate governance research. Review of Financial

Studies, v. 23, n. 3, p. 939-961, 2010.
BORNHOLDT, W. Governança na empresa familiar: implementação e prática. Porto Alegre: Bookman, 2005.

BROUARD, F.; DI VITO, J. Identification des mécanismes de gouvernance applicables aux PME. In: CONGRES INTERNATIONAL FRANCOPHONE EN ENTREPRENEURIAT ET PME, 9, 2008. Conference Proceedings... Louvain-la-Neuve, Belgique, Octobre, 2008.

CARRIERI, A. P.; SARAIVA, L. A. S.; GRZYBOVSKI, D. (Org.). Organizações familiares: um mosaico brasileiro. Passo Fundo: Ediupf, 2008.

CHONG, A.; LÓPEZ-DE-SINALES, F. Corporate Governance in Latin America. Research Department Working Paper Series n. 591. Inter-American Development Bank, March, 2007.

CLARKE, T. Theories of corporate governance. Routledge: New York, 2004.

EMRICH, G.; BAÊTA, A. M. C. A pesquisa no Brasil: o papel do capital empreendedor. Revista USP, São Paulo, n. 73, p. 24-31, mar.-maio, 2007.

EFEICHE, E. Pequenas e médias empresas adotam também a governança corporativa. Investnews/Gazeta Mercantil, 12 fev. 2009. Disponível em: <http://diagono. com.br/leImprensa.asp?idImp $=2>$. Acesso em: 19 set. 2011.

FAMA, E. F. Agency problems and the theory of the firm. The Journal of Political Economy, v. 88, n. 2, p. 288307, 1980.

FAMA, E. F.; JENSEN, M. C. Separation of ownership and control. Journal of Law and Economics, v. 26, n. 2, p. 301-325, 1983.

GIL, A. C. Métodos e técnicas de pesquisa social. 5 . ed. São Paulo: Atlas, 1999.

GONÇALVES, S. C. Patrimônio, família e empresa: um estudo sobre a transformação no mundo da economia empresarial. São Paulo: Negócio, 2000.

\section{GRZYBOVSKI, D.; TEDESCO, J. C. (Org.). Empresa}

familiar: tendências e racionalidades em conflito. Passo Fundo: Ediupf, 2000. 
GUEDES, A. L.; FARIA, A. Entendendo governança internacional: estudo de caso no setor de petróleo.

Organização \& Sociedade, v. 11, n. 31, p. 171-185, set.-dez., 2004.

HE, E.; SOMMER, D. W. Separation of ownership and control: implications for board composition. In: ARIA ANNUAL MEETING, Washington, 2006. Proceding of... Washington, Aug. 2006.

IBCG. Pesquisa sobre governança corporativa. [2011]. Disponível em: <http://www.ibcg.org.br>. Acesso em: 18 jul. 2011.

IBGC/BOOZ ALLEN. Panorama atual da governança corporativa no Brasil. In: CONGRESSO BRASILEIRO DE GOVERNANÇA CORPORATIVA, 4, São Paulo, 2003.

Anais.... São Paulo, nov. 2003.

IBGC/BOOZ ALLEN. Panorama atual da governança corporativa no Brasil. São Paulo, 2010.

JENSEN, M. Maximization, stakeholder theory and the corporate objective function. Boston: Harvard Business School. Working Paper 00-058, abr., 2000.

JENSEN, M. C.; MECKLING, W. H. Theory of the firm: managerial behavior, agency costs and ownership structure. Journal of Financial Economics, v. 3, n. 4, p. 305-360, 1976.

JUDGE, W. The importance of considering context when developing a global theory of corporate governance.

Corporate Governance: An International Review, v. 20, n. 2, p. 123-124, March, 2012.

\section{KRÜGER, I. M.; GOMES, L. S. Governança}

corporativa: estratégia de valor empresarial. Edição Eletrônica. [2011]. Disponível em: <http://www.eumed. net/libros/2010f/864/> . Acesso em: 19 set. 2011.

LI, F; SRINIVASAN, S. Corporate governance when founders are directors. Journal of Financial Economics, v. 102, n. 2, p. 454-469, Nov. 2011.

LODI, J. B. A empresa familiar. 4. ed. São Paulo: Pioneira, 1993.

MARINELLI, M. Um estudo exploratório sobre o estágio da governança corporativa nas empresas brasileiras. Revista

Brasileira de Gestão de Negócios, set.-dez., 2005.
MARTINS, G. A. Estudo de caso: uma estratégia de pesquisa. São Paulo: Atlas, 2006.

\section{MCKINSEY \& COMPANY/KORN/FERRY}

INTERNATIONAL. Panorama de governança

corporativa no Brasil. São Paulo, out., 2001.

MIZUMOTO, F. M.; MACHADO FILHO, C. P. Práticas de governança corporativa em empresa familiar de capital fechado: um estudo de caso. Revista de Negócios, v. 12, n. 2, p. 3-17, abril-junho, 2007.

\section{MONACO, D. C. Estudo da composição dos} conselhos de administração e instrumentos de controle das sociedades por ações no Brasil. 2000. 177p. Dissertação (Mestrado) - Faculdade de Economia, Administração e Contabilidade da Universidade de São Paulo.

MUSTAKALLIO, M. et al. Relational and contractual governance in family firms: effects on strategic decision making. Family Business Review, v. 15, p. 205-227, 2002.

PADULA, A. D. Empresa familiar: profissionalização, desenvolvimento e sucessão. Porto Alegre: SEBRAE, 1998.

PEREIRA, A. N. Resenha crítica Cases in corporate governance. Revista de Educação e Pesquisa em Contabilidade, v. 2, n. 1, p. 111-114, jan.-abr. 2008.

RENDERS, A.; GAEREMYNCK. Corporate governance, principal-principal agency conflicts, and firm value in European Listed Companies. Corporate Governance: An International Review, v. 20, n. 2, p. 125-143, 2012.

SCHUMPETER, J. A. Fundamentos do pensamento econômico. Rio de Janeiro: J. Zahar, 1968.

SIFFERT FILHO, N. Governança corporativa: padrões Internacionais e evidências empíricas no Brasil nos anos 90. Revista do BNDES, v. 5, n. 9, jun. 1998.

SMITH, A. The wealth of nations. New York: Modern Library, 1776.

SOUZA, T. M. G. Governança corporativa e o conflito de interesses nas sociedades anônimas. São Paulo: Atlas, 2005. 
Rodrigo Teixeira Machado • Denize Grzybovski $•$ Enise Barth Teixeira $•$ Margarete David da Silva

YIN, R. K. Estudo de caso: planejamento e métodos. 3.

ed. Porto Alegre: Bookman, 2005.

ZINGALES, L. Corporate governance. In: NEWMAN, P.

(editor). The new palgrave dictionary of economics

and the law. New York: Macmillan, 1998. 